\title{
A REVIEW ON INVESTIGATION OF PROCESS PARAMETERS OF MIG WELDING MACHINE
}

\author{
D.O.I - 10.51201/JUSST/21/09668 \\ http://doi.org/10.51201/Jusst/21/09668 \\ Nikky ${ }^{1}$, Sukhdeep S. Dhami ${ }^{2}$ \\ ${ }^{1}$ M.E. Scholar, 2 Professor \\ Department of Mechanical Engineering \\ National Institute of Technical Teachers Training and Research (NITTTR), Chandigarh
}

\begin{abstract}
This paper discusses about the study of process parameters of MIG welding during the fabrication of a material. The main purpose of this review is; to study the role of various parameters like voltage, welding current, polarity \& shielding gas flow rate etc. on the various expected responses like welding penetration, surface roughness, hardness \& ultimate tensile strength etc. of the finalized material. The literature provides adequate information of the Taguchi/RSM/GRA techniques; responsible for obtaining the suitable orthogonal array design, followed by the priority of the process parameters; responsible for optimization of the experimental responses. Also, it has reviewed that ANOVA plays an important role in analysing the response table. With this review, a well-defined experiment can be executed to get the desired optimal responses.
\end{abstract}

Keywords: MIG Welding, Material, Optimization, Anova, Process Parameters, Responses.

\section{INTRODUCTION}

Metal Inert Gas (MIG) welding embraces a group of arc welding processes in which a continuous electrode (the wire) is fed by powered feed rolls (wire feeder) into the weld pool. An electric arc is created between the tip of the wire and the weld pool. The wire is progressively melted at the same speed at which it is being fed and forms part of the weld pool. Both the arc and the weld pool are protected from atmospheric contamination by a shield of inert (non-reactive) gas, which is delivered through a nozzle that is concentric with the welding wire guide tube.

\section{MIG WELDING OPERATION}

Schematic Diagram of MIG Welding is shown in Fig 1. MIG welding is usually carried out with a handheld gun as a semiautomatic process. The MIG process can be suited to a variety of job requirements by choosing the correct shielding gas, electrode (wire) size and welding parameters. Welding parameters include the voltage, travel speed, arc (stick-out) length and wire feed rate. The arc voltage and wire feed rate will determine the filler metal transfer method. This application combines the advantages of continuity, speed, comparative freedom from distortion and the reliability of automatic welding with the versatility and control of manual welding. 


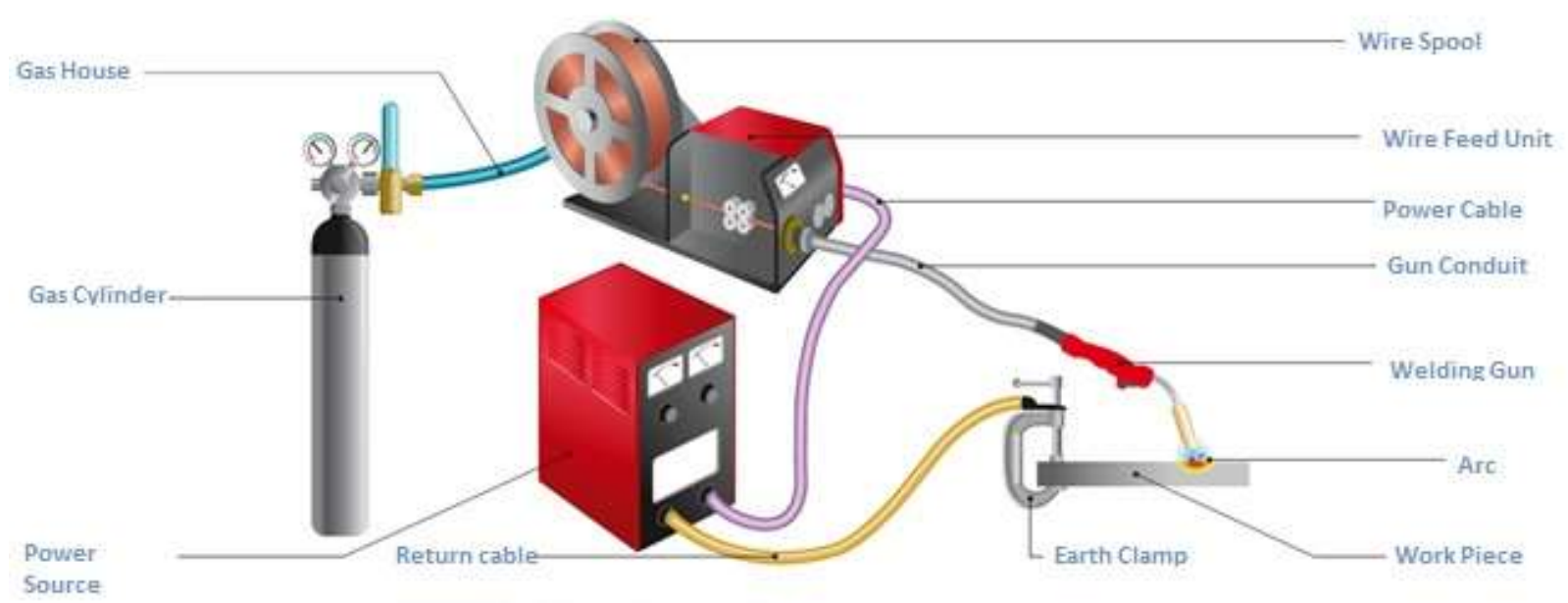

Fig. 1

\section{MIG WELDING PROCESS PARAMETERS}

The welding process variables mainly affect the geometry of the weld bead such as the penetration, bead reinforcement, bead width and the deposition rate, which is the weight of the metal deposited per unit of time. These variables are as:

Welding Current: The value of welding current used in MIG has the greatest effect on the deposition rate, the weld bead size, shape and the penetration. In MIG welding, metals are generally welded with direct current polarity electrode positive, because it provides the maximum heat input to the work and therefore a relatively deep penetration can be obtained.

Welding Voltage: The arc length is one of the most important variables in MIG that must be held under control. When all the variables such as the electrode composition and sizes, the type of shielding gas and the welding technique are held constant, the arc length is directly related to the arc voltage.

Welding Speed: The travel speed is the rate at which the arc travels along the work-piece. It is controlled by the welder in semiautomatic welding and by the machine in automatic welding. The effects of the travel speed are just about similar to the effects of the arc voltage. The penetration is maximum at a certain value and decreases as the arc speed is varied.

Types of Shielding Gas: As mentioned before, different types of shielding gases are used in the MIG process, and the melting rate, bead profile and penetration of weld changes due to gas type. At the same time, the type of the shielding gas affects the spattering, welding speed and the mode of metal transfer and thus the overall mechanical properties of the weld metal. 


\section{PROBLEMS ASSOCIATED WITH MIG WELDING}

The welding operation is associated with a number of obstacles during the operation. Some of them can be discussed as:

Excess/Lack of Penetration: Excessive or inadequate heat input can lead to the weld metal melting through the base metal. To resolve the issue, the best possible ratio for the welding variables like voltage, current, shielding gas etc. These variables are set as per differ as per welding material work piece and required weld quality.

Welding Spatter: The weld puddle can expel molten metal and leave the spatter along the bead. This affects the weld appearance and the strength of the fusion. Spatters can be caused by high wire feed speed and high voltage settings for welding process. Other include the insufficient use of gas and dirty base material.

Inadequate Shielding Gas Problem: Another very common cause of porosity in MIG welding is inadequate shielding gas coverage. This welding process relies on the use of shielding gas for protecting the molten metal weld pool from environmental contaminants. Without proper shielding gas protection, the air can contaminate the molten metal weld pool and result in porosity and other welding defects.

\section{LITERATURE REVIEW}

Some of important research work has been studied below to understand the present status of research and further steps needed for improvement.

D. Kim et al. [1] performed the study for determination of Optimal Welding Conditions with a Controlled Random Search Procedure. In this experiment, input variables were the wire feed rate, welding voltage, and welding speed, while the output variables were the front bead height, back bead width, and penetration of the bead geometry.

Erdal Karadeniz et al. [2] investigated the effects of various welding parameters on welding penetration in Erdemir 6842 steel having $2.5 \mathrm{~mm}$ thickness welded by robotic gas metal arc welding. The welding current, arc voltage and welding speed were chosen as variable parameters. The depths of penetration were measured for each specimen after the welding operations and the effects of these parameters on penetration were researched. 
N.B. Mostafa et al. [3] performed research to predict weld penetration as influenced by FCAW process parameters of welding current, arc voltage, nozzle-to-plate distance, electrode-to - work angle and welding speed. Optimization of these parameters to maximize weld penetration was also investigated.

Bipin Kumar Srivastava et al. [4] reviewed and discussed that mechanical properties of weld are influenced by the composition of the base metal and to a large extent by the weld bead geometry and shape relationship as well. They also observed that with increase in electrode stick out, hardness of the weldment increases.

Ajit Hooda et al. [5] investigated the optimization of MIG welding process Parameters to predict maximum yield Strength in AISI 1040. They applied RSM technique for optimizing the MIG welding process parameters to attain the maximum yield strength of the joint.

Izzatul Aini Ibrahim et al. [6] performed a study on Effect of Gas Metal Arc Welding processes on different welding parameters. They took arc voltage, welding current and welding speed as their welding variables and performed experiment using $6 \mathrm{~mm}$ thick mild steel sheet.

Mohd. Shoeb et al. [7] have performed a study on various welding parameters such as welding speed, voltage and gas flow rate for HSLA steel and the effects of these parameters on weld bead geometry such as penetration, width $\&$ height. They concluded that penetration increased gradually with increase in voltage and reaches a maximum value.

P. Kah et al. [8] reviewed developments and new innovations in terms of novel concepts in the field of gas metal arc welding process, particularly the effect of the setup of the welding process parameters on waveform deposition.

P.E. Murray \& A.Scotti [9] performed a research on depth of penetration in Gas Metal Arc welding. Their research was based on the model that heat and mass transfer to the weld pool and the depth of penetration might be correlated by a dimension relation. The experiment result showed that depth of penetration was affected by rate of mass transfer.

Milind M. Ghogale \& Prof. S. A. Patil [10] investigated to determine the optimum welding conditions to get highest penetration in welding. They conducted experiments on penetration by varying current, voltage, gas flow, fixture rotation speed and wire feed rate using OVAT method. They found that an increase of current generally improved penetration depth 
C. Labesh Kumar et al. [11] carried out a study to optimize welding parameters like welding current, welding voltage, Gas flow rate and wire feed rate using DOE method. They used plan of experiments based on Taguchi technique to acquire the data. An Orthogonal array, signal to noise $(\mathrm{S} / \mathrm{N})$ ratio and analysis of variance (ANOVA) was employed to study the welding characteristics of material \& optimizing the welding parameters.

\section{CONCLUSION}

Many researchers have worked on different type of materials with various types of design of experiment (DOE) technique such as Taguchi, Response Surface method etc. Also effect of various process parameters like Electrode size, Welding current, Arc voltage, Arc travel speed, Welding position, Gas Flow rate, Shielding Gas composition was studied on various materials and its effect on output parameters like tensile strength, hardness was studied. From this literature review, it is found that with proper optimization of process parameters of MIG welding precise output with high production can be obtained. The conclusive remarks are very beneficial to the industry people.

\section{REFERENCES}

[1] D. Kim, M. Kang, And S. Rhee, Determination of Optimal Welding Conditions with a Controlled Random Search Procedure, welding journal 2005, 125-s to 129-s.

[2] Erdal Karadeniz, Ugur Ozsarac, Ceyhan Yildiz, The Effect Of Process Parameters On Penetration in Metal Arc Welding Processes, Elseveir Science Direct Materials and Design 28 (2007) 649-656.

[3] N.B. Mostafa , M.N. Khajavi ,2006, Optimization Of Welding Parameters For Weld Penetration in FCAW,AMME Journal of Achievements in Materials and Manufacturing Engineering, VOLUME 16 ISSUE 1-2 May-June 2006.

[4] Bipin Kumar Srivastava, S.P. Tewari, Jyoti Prakash, A Review On Effect Of Arc Welding Parameters On Mechanical Behavior Of Ferrous Metals/Alloys, International Journal of Engineering Science and Technology,Vol. 2(5), 2010, 1425-1432.

[5] Ajit Hooda, Ashwani Dhingra, Satpal Sharma, Optimization Of MIG Welding Process Parameters To Predict aximum Yield Strength in AISI 1040, IJMERR Vol. 1, No. 3, October 2012.

[6] Izzatul Aini Ibrahim, Syarul Asraf Mohamat, Amalina Amir And Abdul Ghalib, The Effect of Gas Metal Arc Welding (GMAW) Processes On Different Welding Parameters, Elsevier Engineering Procedia, International Symposium on Robotics and Intelligent Sensors 2012 (IRIS 2012)

[7] R. Suoranta \& J. Martikainen, Advanced Gas Metal Arc Welding Processes, Springer Int J Adv Manuf Technol (2013) 67:655-674,DOI 10.1007/s00170-012-4513-5.

[8] P.E. Murray \& A.Scotti, Depth of Penetration in Gas Metal Arc Welding, Science and Technology of welding and joining2014,ISSN1362-1718.

[9] Milind M. Ghogale \& Prof. S. A. Patil, Ovat Analysis for Improving Weld Quality in MIG Welding, International Journal of Engineering Research \& Technology (IJERT)

Vol. 3 Issue 8, August - 2014, IJERTIJERT, ISSN: 2278-0181.

[10] Akash Srivastava Sumeet Sekhar, Prayass Rai, Anusheen Nema, Ayush Pandey, Roshan Jha, Arif Ayub ,Analysis of Welding Joints and Processes, International Journal of Computer Applications (0975 - 8887), International Conference on Advances in Emerging Technology (ICAET 2016).

[11] C. Labesh Kumar, T. Vanaja, Dr. Kgk Murti, Vvsh Prasad, Optimization of MIG Welding Process Parameters for Improving Welding Strength of Steel, International Journal of Engineering Trends and Technology (IJETT) - Volume 50 Number 1 August 2017. 